\title{
Estórias e Trajetórias que Desenham com Arte Lugares e Corpos
}

\author{
Historias y Trayectorias que dibujan con Arte Lugares y Cuerpos \\ Stories and trajectories that draw with art places and bodies.
}

\author{
Adilson Crepalde ${ }^{1}$ \\ Cecília Maria Pinto do Nascimento ${ }^{2}$
}

\begin{abstract}
Resumo
Este trabalho consiste em uma reflexão interdisciplinar sobre os processos de construção de espaços no contexto da cultura kaiowa no Mato Grosso do Sul, Brasil. As reflexões são realizadas com base em explicações dos próprios Kaiowa sobre o significado da expressão tekoha (lugar onde se produz o modo de ser) que foram coletadas e utilizadas como objeto de estudo em uma tese de doutoramento sobre significação. Objetiva-se refletir sobre as nuanças da dinâmica dos processos de construção de espaços no âmbito da cultura kaiowa por meio de uma abordagem interdisciplinar. Para tanto, apoiou-se nas reflexões sobre o caráter relacional e dinâmico da construção do espaço realizadas no âmbito da Geografia; na teoria da corporificação da Linguística Cognitiva; nas considerações sobre fronteiras étnicas realizadas na Antropologia Processualista e de conhecimentos historiográficos e antropológicos sobre a cultura kaiowa utilizados na tese de doutoramento acima referida. As reflexões desenvolvidas no trabalho possibilitaram delinear, ainda que parcialmente, a maneira kaiowa de construir espaços, um conjunto de processos complexos de relações e em devir que denominamos tekohalização.
\end{abstract}

Palavras-Chave: espaço; cultura; interdisciplinaridade; tekohalização.

\section{Resumen}

Este trabajo consiste en una reflexión interdisciplinaria sobre los procesos de construcción de espacios en el contexto de la cultura kaiowa no Mato Grosso do Sul (MS), Brasil. Las reflexiones son realizadas basadas en explicaciones sobre el significado de la expresión tekoha (lugar donde se produce el modo de vivir.) que fueran colectadas y utilizadas como objeto de estudio en una tesis de doctoramiento sobre significación. Objetivase reflexionar sobre las sutilezas de la dinámica de los procesos de construcción de espacios en el ámbito da cultura kaiowa, haciéndose uso de una abordaje interdisciplinaria. Para esto, apoyase en reflexiones sobre el carácter relacional y dinámico de los procesos de construcción de espacios hechas en el ámbito de la Geografía; en la teoría de lo embodiment de la Lingǘstica Cognitiva, en las ponderaciones sobre fronteras étnicas de la Antropología Procesalista y de conocimientos antropológicos e historiográficos sobre la cultura kaiowa utilizados en la referida tesis de doctoramiento. Las reflexiones hechas en el trabajo posibilitaran delinear, aunque de manera parcial, la manera kaiowa de construir espacios, un conjunto de procesos complejos de relaciones y en devenir que lo denominamos tekohalización.

Palabras claves: espacio; cultura; interdisciplinaridad; tekohalización.

\begin{abstract}
This work consists of an interdisciplinary reflection on the processes of spaces building in the context of the kaiowa culture in Mato Grosso do Sul, Brazil. The reflections were based on the explanations of the meaning of the expressions tekoha (place where a way of living is built) that were collected and used as study object in a
\end{abstract}

\footnotetext{
${ }^{1}$ Professor de Língua Inglesa e Estágio do Curso de Letras, Português/Inglês da Universidade Estadual de Mato Grosso do Sul. E-mail: crepalde@uems.br

${ }^{2}$ Professora de Física e Estágio do Curso de Licenciatura em Física da Universidade Estadual de Mato Grosso do Sul. E-mail: cmpn.ci@gmail.com.
} 
doctoral thesis on signification. The objective in the paper is to reflect about the subtleties of the dynamics of spaces building processes in kaiowa culture scope by using an interdisciplinary approach. To do so, we relied on reflections about the relational and dynamic aspects of building spaces processes carried out in the Geography scope. We also relied on the theory of embodiment from the Cognitive Linguistics, and on reflections on ethnic boundaries done in the Processional Anthropology context as well as on historiographic and anthropological information used in the above mentioned thesis. We can say that the reflections developed in this work could delineate, even in a partial way, the kaiowa way of building spaces, a set of complex and ever-changing processes, which we named tekohalization.

Keywords: space; culture; interdisciplinarity; tekohalazation.

\section{Introdução}

Este trabalho trata-se de um estudo sobre a construção do significado de espaço no contexto da cultura kaiowa ${ }^{3}$ (ASSIS, 2000) neste momento histórico. O estudo consiste em reflexões sobre as explicações que os indígenas kaiowa deram sobre o significado da expressão tekoha, que tem sido traduzida, grosso modo, na literatura historiográfica e antropológica, como o espaço, o lugar onde os Kaiowa constroem o seu modo de ser. Tais explicações foram coletadas em entrevistas orais e participativas com os kaiowa para a realização de uma tese sobre significação (CREPALDE, 2014).

Trata-se de um estudo interpretativo que leva em consideração os signos linguísticos e não linguísticos que tramam as representações dos Kaiowa. A leitura das referidas explicações e informações antropológicas sobre a cultura kaiowa (BENITES, 2012) demonstram a complexidade do modo kaiowa de ser e representar. Diante dessa complexidade, entendemos que algumas reflexões teóricas, que havíamos feito para pensar sobre as categorias espaço, tempo, representações e construção de sentido, pudessem nos ajudar a refletir sobre os significados dos Kaiowa de espaço.

Dessa maneira, optamos pelas reflexões desenvolvidas no âmbito da Linguística Cognitiva (LC), sobretudo no que diz respeito à Hipótese da Corporificação e dos pensamentos metafóricos, que remetem à construção de significados não apenas arbitrários, mas também motivados, significados que se constroem no andar pelo mundo, na interação

\footnotetext{
${ }^{3}$ As palavras da avañe'é, expressão usada pelos Kaiowa para nomear sua língua, neste trabalho, seguem a grafia e a prosódia do dicionário Ñe'ẽ Ryru Avañe 'ẽ: dicionário Guarani-Português. Serão acentuadas somente as expressões paroxítonas. A expressão "kaiowa", dessa maneira, não será acentuada e será grafada com "w", em maiúscula e sempre no singular quando for empregada como nome do grupo étnico e será grafada em minúscula quando for empregada como adjetivo. A expressão guarani será empregada em maiúscula quando for empregada para nomear o grupo étnico e em minúscula para nomear a língua, em referência à lingua da qual deriva a avañe'ẽ. Todas as expressões serão grafadas em itálico, exceto as expressões Kaiowa e Guarani ao se referirem aos grupos étnicos. No entanto, todas as expressões serão grafadas no singular inclusive as expressões Kaiowa e Guarani.
} 
entre corpos e o meio ambiente (KÖVECSES, 2005; GIBBS, 2006; LAKOFF; JOHNSON, 2003). Optamos por seguir essa linha de pensamento, haja vista as inúmeras metonímias e metáforas empregadas nas explicações, relacionando o domínio corpo humano e o domínio meio ambiente.

Entendemos que esse aporte teórico ajudaria a pensar o modo kaiowa de pensar e representar; entretanto, teríamos que recorrer a outras teorias que nos auxiliassem a refletir sobre a complexa rede de relações entre humanos e entre humanos e não humanos que compõem a dinâmica dos processos de construção de espaços evocados pela expressão tekoha. Assim, apoiamo-nos nas considerações de Massey (2009), que destaca o caráter relacional, dinâmico e em devir desses processos, chama a atenção para os conflitos e para as incertezas que os permeiam e dá ênfase ao político como maneira de configurar espaços sempre incompletos. Para a autora,

E se o espaço for a esfera não de uma multiplicidade discreta de coisas inertes, ainda
que completamente inter-relacionada? E se, ao contrário, ele nos apresentar uma
heterogeneidade de práticas e processos? Então ele não será um todo já-
interconectado, mas um produto contínuo de interconexões e não-conexões (sic).
Assim, ele será sempre inacabado e aberto. Esta arena do espaço não é um terreno
firme para ficar. Não é, de forma alguma, uma superfície. (MASSEY, 2009, p. 160)

No entanto, ainda que Massey (2009) possibilite pensar na dinâmica das relações e chame a atenção para as relações culturais e a interpenetração do local com o global, sentimos a necessidade de buscar apoio em outros aportes teóricos para pensar os processos de relações interculturais que os Kaiowa vivenciam nos dias atuais.

Nesse sentido, buscamos apoio nas ponderações de Barth (1993) sobre fronteiras étnicas que permitem pensar em fronteiras fluidas e, ao mesmo tempo, em limites que se constroem nos jogos de pertença. Essas fronteiras étnicas circunscrevem um conjunto de valores, uma linguagem, formas de julgamento, formas de organização social, práticas sociais, etc. que permitem que aqueles que vivem dentro delas se reconheçam. Essas ponderações de Barth são utilizadas na antropologia de Benites (2012), um antropólogo kaiowa cujos trabalhos captam as sutilezas de sua própria cultura e trazem reflexões extremamente relevantes sobre o modo de ser Kaiowa deste momento histórico.

Além dos dados etnográficos de Benites, valemo-nos também das informações historiográficas e antropológicas utilizadas na já referida tese sobre significação (CREPALDE, 2014), na qual se encontram alusões ao modo de ser kaiowa com base em antropólogos e historiados considerados canônicos. 
Dessa maneira, o objeto de estudo foi pensado com base em diferentes áreas do conhecimento, numa tentativa de refletir sobre como os kaiowa contemporâneos têm elaborado o significado de espaço. A abordagem interdisciplinar do objeto de estudo foi cogitada em momentos de reflexão de um projeto de pesquisa que visa a refletir sobre as possibilidades, os limites e as dificuldades de se pensar as representações da realidade por meio de uma perspectiva interdisciplinar. O grupo que pensa o projeto de pesquisa tem realizado discussões sobre categorias, como espaço, tempo e ficção científica, das quais surgem proposições de trabalhos. E, dessa maneira, surgiu o objeto de estudo deste trabalho que está dividido em três partes.

$\mathrm{Na}$ primeira parte, denominada um olhar sobre os Kaiowá, fazemos uma contextualização sobre os Kaiowa do Mato Grosso do Sul deste momento histórico com base no trabalho de Benites (2012) que coloca o modo de ser no plural, ou seja, remete a vários modos de ser elaborados por trajetórias diferentes das famílias extensas, grupo macrofamiliar e organização social básica desses indígenas.

$\mathrm{Na}$ segunda parte, refletimos sobre o objeto de estudo com base nas considerações teóricas. Essa segunda parte, subdivide-se em duas: uma denominada o vir a ser tekoha, na qual discutimos os processos de construção dos espaços como algo que emerge das relações entre humanos e não humanos, fazendo vir a ser um lugar, um espaço de pertença, uma cultura deste tempo presente, porém impregnada de passado. Na outra subparte, denominada tekoha em relações, refletimos sobre a dinâmica desses processos, dando ênfase à política kaiowa e às relações interculturais que se realizam dentro de um cenário complexo e conflituoso que exige dos Kaiowa luta constante por suas terras e pelo seu modo de ser.

Esse andar, esse mover kaiowa pelo mundo, pelas terras sul-mato-grossenses, que deixa um rastro inscrito em signos linguísticos e não linguísticos, sugerimos que seja denominado tekohalização. Por fim, fazemos as considerações finais que denominamos considerações jamais-finais, porque entendemos que refletir sobre a dinâmica de processos de construção de espaços é tarefa sempre a ser feita, haja vista a eventualidade dos movimentos e a quantidade de variáveis que são postas em jogo, sobretudo no caso Kaiowa.

\section{Um olhar sobre os Kaiowa}

Os Kaiowa do Mato Grosso do Sul (MS) têm lutado por suas terras e construído seu espaço de pertença, sua cultura, com bens materiais e simbólicos tradicionais e novos adquiridos dos contatos com outras culturas, um contato marcado por atitudes solidárias, mas 
também por conflitos. Desses contatos-conflitos interculturais, porém com base no teko ymaguare, modo de ser tradicional, emerge o teko pyahu (o modo de ser novo, contemporâneo). O modo de ser tradicional configura-se em uma forma de interação social, de relação com o sobrenatural, com o meio ambiente e uma forma de construir representações sobre a experiência que se difere de outras, dando as bases sobre as quais elaboram um modo de ser que hoje se constrói, sobretudo em relação de oposição ao modo karai (não índio) de ser.

O contato-conflito com outras culturas os levou a desenvolver conhecimentos, linguagens e habilidades para atuarem nesses espaços interculturais. Todavia, não se pode pensar nesse processo como algo homogêneo que atravessa todos os kaiowa do MS. Isso porque a base social desses indígenas ainda é, nos dias atuais, a família extensa - grupo macrofamiliar, composto por membros consanguíneos e agregados sob o comando de um líder ou uma líder -, e cada família extensa desenvolve seu próprio teko laja (modo de ser específico de cada família) (BENITES, 2012).

Cada família extensa traça sua própria história, formulando suas estratégias de luta, dando sentido às suas experiências e elaborando justificativas para as mudanças pelas quais passam. Além disso, há famílias extensas vivendo situações diferentes em reservas, terras retomadas, terras em litígio e até em beira de estradas, sem contar que essas mesmas famílias disputam bens materiais e prestígio político entre si. Essas diferenças, no entanto, não impedem que se reconheçam como membros do mesmo grupo étnico, produtores do nãnde reko (nosso modo de ser).

Esse reconhecimento entre as famílias extensas kaiowa desdobra-se, muitas vezes, em relação às famílias extensas Guarani, grupo étnico com o qual os Kaiowa mantêm estreitas relações sociais e políticas. Esses grupos étnicos organizam-se de maneira parecida e falam variações da língua guarani e até casam-se entre si. Além de relações com os Guarani, os Kaiowa, também, se relacionam com outros grupos étnicos, como os Terena, por exemplo, com quem compartilham a vida cotidiana em uma das reservas de MS e em movimentos políticos.

A longa convivência com os não índios tem possibilitado a aprendizagem das línguas portuguesa e espanhola, a incorporação de bens materiais, hábitos alimentares e tem os levado a se comportar no mundo do trabalho dos não índios. Eles têm, também, praticado outras religiões e passado por um processo de ensino-aprendizagem que lhes ensina noções de 
tempo, de espaço, de quantidade, de qualidade, de ética, de estética, etc. muito diferente das que seus avós elaboraram ao longo do tempo.

Ademais, o acesso à televisão, ao rádio e à internet tem lhes possibilitado entrar em contato com culturas distantes. Dessa maneira, os Kaiowa produzem suas vidas em um espaço multicultural construindo o ñade reko (nosso modo de ser) como resultado de vários teko laja (modo de ser de cada família extensa) e de vários teko reta (modo múltiplo de ser) (BENITES, 2012).

A expressão teko reta evoca a dinâmica de um modo de ser multicultural que lança mão de linguagens e estratégias variadas para produzir a cultura Kaiowa deste momento histórico. Uma cultura, um espaço cultural que se reinventa, apesar da escassez de espaço físico nas reservas e fora delas, que possibilita aos Kaiowa contemporâneos manterem seus laços de pertença e fazer vir a ser seus tekoha.

A fala abaixo de uma participante da pesquisa ilustra a dinâmica do modo de ser kaiowa contemporâneo do qual fala Benites (2012) ${ }^{4}$ :

Yvypóra é gente, né? Omano jave oho Ñandejára ndive (Quando a gente morre vai morar com nosso Deus). Ha'e ohoma (Ele já está lá.). Nande, ava, jamano jave jaha overáva chiru ipoguasua (Nós, os ava, ao morrermos vamos para um lugar grande e brilhante junto com nosso Deus.). Koãnga mitã oiestudia ndoiporiveíma ymaguare (Agora, na escola, as crianças estudam, mas lá não falam de nossos ancestrais)

Observamos no trecho acima, a influência do espanhol por meio da expressão "gente", pronunciada /rente/, e pela expressão “oistudia” (Eles estudam), adaptação do verbo "estudiar", conjugado de acordo com o guarani, ou seja, recebe a marca "o" no início do verbo que indica terceira pessoa do plural. Em guarani, as marcas que indicam a pessoa verbal vêm no começo do verbo. Assim, che aistudia (eu estudo), nde restudia (você estuda), etc. Observa-se também o uso do verbo "é" e a expressão "né" indicando a influência do português. A língua kaiowa falada, hoje, tem um grande número de empréstimos e tem sofrido influência em termos morfológicos, sintáticos, semânticos e fonológicos. Por conta dessas influências, os próprios Kaiowa têm denominado a língua atual jopora (mistura), contrapondo-a a avañe'ẽ, a língua dos ancestrais. A passagem ainda demonstra a situação de interculturalidade em que vivem ao ser referir à escola, ao que se aprende lá e, ao mesmo tempo, remete a uma explicação sobre as relações com o sobrenatural, segundo o modo

\footnotetext{
${ }^{4}$ Optamos por utilizar parte das falas dos participantes da pesquisa para ilustrar e reforçar os argumentos deste trabalho. Tais trechos foram colocados em caixas de tabela com o intuito de destacá-los do corpo do texto.
} 
kaiowa de ser. Essas observações podem ser constatadas em todos os exemplos das falas dos kaiowa utilizadas neste trabalho.

A expressão tekoha composta de teko (modo de ser, estar vivo) e ha (partícula que faz alusão ao espaço físico) evoca toda essa dinâmica que atravessa os processos de construção de espaços que, neste trabalho, denominamos tekohalização. Trata-se de um movimento que reivindica e traça um território e esculpe um lugar e um modo de ser cuja complexidade não cabe em categorias rígidas, haja vista a sutileza dessa dinâmica de produção de vida, que se impõe como uma maneira alternativa e diferente em relação a outras.

\section{O vir a ser tekoha}

Com base nas informações antropológicas e historiográficas e nas conversas com os Kaiowa podemos dizer que tudo que existe está integrado em uma rede de relações: humanos, plantas, espíritos, pedras, rios, tudo faz parte dessa rede. Os Kaiowa entendem que o terreal e o sobrenatural são indissociáveis e que a interação entre os seres humanos e entre humanos e não humanos são mediadas por forças sobrenaturais.

Os depoimentos falam de como os ancestrais criaram o mundo, organizaram-no, interagiram com ele e comportaram-se, inaugurando um gesto que deve ser imitado. As ações dos seus ancestrais passam a ser metáforas de base, ou seja, premissas por meio das quais elaboram justificativas para as vicissitudes do mundo. A passagem abaixo é uma das explicações sobre o surgimento do mundo:

Pe jasuka ha'e okambu. (Se alimentou de jasuka) Jasuka, matéria da vida. Ñande yvy Ñanderu oñepyrũ koa upecha (Nossa terra. Nosso Ñanderu começou assim). Ha'e, ñamoi Pa'i Kuaraha, ara voi oñepyrũ. (Ele, nosso avó Pa’i Kuaraha, começou um tempo). Entonce... Pa'i kuaraha opyso ko tekoha yvy apy. (Então Pa'i Kuaraha estendeu esse tekoha). Então, mais ou menos assim oguereko pochito, ñande Sy, ha'e, ko yvy opyso upea ko ojehu porã ha upe rupi (Então, foi mais ou menos assim que aconteceu, nossa mãe, vestida com o ponchito desdobrou o tekoha ). Oĩma ko chiru, Oĩ y, yvy, oĩ teko, oguereko ararivy oĩ yvyra'i. (Já havia o chiru, a água e a terra e a cultura).

Esse entrelaçamento ocorre por meio de uma linguagem que inclui signos linguísticos e icônicos que são empregados nas práticas diárias, em rezas, em danças e em rituais. Em vários tekoha foram vistos elementos culturais que usam para dialogar com as forças sobrenaturais, como mbaraka (chocalho de cabaça), chiru (o símbolo mais sagrado e poderoso representado por varas e cruz de madeira), takuapu (bastão feito de bambu, usado por mulheres), dentre outros. Essa linguagem, segundo os participantes, é a maneira de estabelecerem o equilíbrio entre os elementos dos mundos terreal e sobrenatural e praticar o 
teko porã (modo adequado de ser). Na passagem abaixo, pode-se observar como os Kaiowa buscam sua segurança e equilíbrio por meio do purahei (canto) e dos instrumentos sagrados, valendo-se do poder de seus ancestrais.

Koãnga odividi cada mundo, oime São Paulo (Agora tem vários espaços, tem São Paulo). Ou karai (Vieram os brancos). Ava ndoguerokoi fazenda (Os Guarani-Kaiowa não têm fazenda). Ava ndomba'eveguerekoi pelo so que ha'e tá seguro ñande Ñanderu ha ñande Sy pe seguro (Os Guarani-Kaiowa não têm, mas estão seguros com nosso Pai e nossa Mãe, ancestrais). Ore opurahei oreguereko mbaraka oreguereko chiru, oreguereko takuapu (Nós temos nossa reza, nosso chocalho, nosso chiru, nosso takuapu). Purahei osegura hangua ichupe (Koãnga purahei'ỹ voi vira ovira já pronto). Hoje em dia, sem nossa reza verdadeira, o mundo pode se desequilibrar. (Fala de um dos participantes da pesquisa).

No entanto, o equilíbrio também tem a ver com as condições concretas de produção da vida kaiowa. O tekoha em equilíbrio foi definido por um dos participantes como "um grande saúde", um estado de tranquilidade e de abundância de alimentos, de condições ambientais, de possibilidade de se locomover para praticar sua cultura e sua política.

O significado da terra é que ali é uma mãe, é um criador. Por exemplo, assim. Se eu não tenho terra como é que eu vou prantar? Como é que eu vou ter saúde. Por que saúde não é só tomar remédio e acabou a dor de cabeça. Eu não tenho nenhum lugar para eu prantar. Então, a saúde envolve milhares de coisas. Por exemplo, para o kaiwoá está bem, ele tem de ter a terra demarcada; ele tem de ter liberdade de vida, de vive. Vou te dar um exemplo em Dourados. Passei por lá em 1972. Eu era guri ainda, passei por lá. Meu pai tava internado lá na Missão Kaiowá. Era mato. Se lembra disso (referindo-se ao João). Aquele Antônio Gordo contratou o próprio índio para tirar madeira lá dentro, para lapinar aruera. Isto foi em 72 . Eu me lembro muito bem. Aí, hoje, o que tá virando Dourados? Vila. Não tem lenha. Isto é saúde? Não é saúde. Tem de ter boa habitação. É lugar de pranta, de colher e de ter liberdade.

Nesse sentido, os tekoha não são apenas superfícies, espaços físicos, mas espaços relacionais e uma linguagem com sua gramática que organiza os diferentes elementos que a compõem. Os depoimentos falam de como os ancestrais criaram o mundo, organizaram-no, interagiram com ele e comportaram-se, inaugurando um gesto que deve ser imitado.

Além das referências a seus mitos, a fala dos Kaiowa remete também à construção da cultura, enquanto um conjunto de padrões cognitivos, linguísticos, comportamentais, éticos, estéticos, etc., elaborada na experiência, no andar pelo mundo. Com base nesses padrões, os Kaiowa criam condições de sobrevivência e um espaço de pertença dinâmico e em devir e reatualizam constantemente esses padrões de acordo com as vicissitudes da experiência no mundo. Pelo que foi dito pelos participantes, podemos dizer que o modo de pensar dos kaiowa é bastante flexível, permitindo elaborar as mais variadas justificativas. Uma forma de pensar que gera significado nas contradições e rupturas do processo. 
A linguagem usada por esses indígenas evoca imagens armazenadas na mentalidade coletiva historicamente construída e as coloca em ação nos jogos dialógicos. Nesses jogos, vale toda sorte de explicação mítica para justificar as instabilidades da vida. As explicações foram feitas parte em português e parte em avañe'ẽ (língua kaiowa), e foi possível coletar inúmeras expressões metonímicas e metafóricas que permitem refletir sobre a maneira kaiowa de pensar o mundo. As expressões metafóricas falaram dos lábios da terra, do cabelo das árvores, da carne-terra, da Mãe-terra, do abraço das árvores, do poder de sedução do arco-íris, etc..

Os Kaiowa falaram, também, do comportamento e da linguagem da natureza com a qual mantem diálogos constantes. Pode-se inferir disso que, para os Kaiowa, a natureza fala por meio de signos impressos em folhas, sementes, flores, movimentos dos ventos, das nuvens, etc.. A natureza, também, inspira a formulação de simpatias e explicações sobre fenômenos humanos, como casamento, sedução, passagem da idade infantil para a adulta, etc. Elementos da natureza são personificados, e os humanos podem assumir formas naturais. Os Kaiowa entendem que a natureza joga politicamente, impondo seu poder por meio de frios, chuvas, relâmpagos, com quais os Kaiowa precisam negociar, pois cada força tem um jára (dono), uma entidade que a comanda e com a qual é preciso dialogar.

Essas explicações, que remetem a um conhecimento elaborado na prática, levam a pensar no conceito de significado corporificado (LAKOFF; JOHNSON, 2003; GIBBS, 2006; KÖVECSES, 2005), um significado construído sócio-historicamente e em relação com o meio ambiente. Na linha de raciocínio da LC, os significados são elaborados no andar pelo mundo, no atrito entre corpo e mundo (CREPALDE, 2014). As noções e conceitos elaborados na experiência coletiva são formados no tatear, no cheirar, no ouvir, no experimentar, no ver o mundo. $\mathrm{O}$ conhecimento não é apenas resultado de um sistema abstrato da mente, que processa as informações matematicamente. O conhecimento é motivado, tem cheiro, tem cor, sabor, etc., e é elaborado de maneiras diferentes. Cada comunidade desenvolve uma maneira específica de perceber, de pensar e simbolizar a experiência coletiva, dependendo do espaço físico em que se encontra. E, segundo a fala dos kaiowa, a cultura, o meio ambiente e o corpo humano kaiowa emergem desse contato carregado de conflitos e de emoções. É no contato com o mundo que geram significados de quantidade e profundidade, de espaço, de tempo, etc.. Assim, o tekoha é muito mais que um suporte para o movimento, é muito mais que uma área geograficamente delimitada, é um espaço-tempo, um espaço vivo levantado na interação 
entre humanos e entre humanos e não humanos como resultado da vida prática e justificado miticamente.

\section{Entrelaçamento do espaço}

Podemos dizer também que as explicações dos Kaiowa permitem pensar o tekoha como um rastro de relações que evoca noções desenvolvidas sócio-historicamente que só podem ser compreendidas dentro do contexto da cultura desses indígenas. As explicações dos Kaiowa levam a pensar na construção do tekoha como o que Massey (2009) denomina de "multiplicidade dinâmica", uma unidade política e heterogênea, com fronteiras fluidas da qual todos os membros participam na tomada de decisões, ainda que assimetricamente. Pela fala dos Kaiowa, essa multiplicidade dinâmica tem seu epicentro na família extensa que entrelaçam suas estórias e trajetórias formando uma rede de relações. Essa rede gera uma noção de espaço mais amplo, um tekoha que abarca o ñande reko (nosso modo de ser), forjado pelo jeito múltiplo de ser (teko reta). Assim, o tekoha deve ser pensado como um espaço que resulta das relações que se constroem a começar da família extensa, mas também como um lugar mais amplo (tekohaguasu), marcado pelas relações entre as famílias extensas e entre elas e outras culturas que as atravessam. Essa rede de relações foi representada por um dos participantes da pesquisa e trazida neste trabalho por meio da Figura 1.

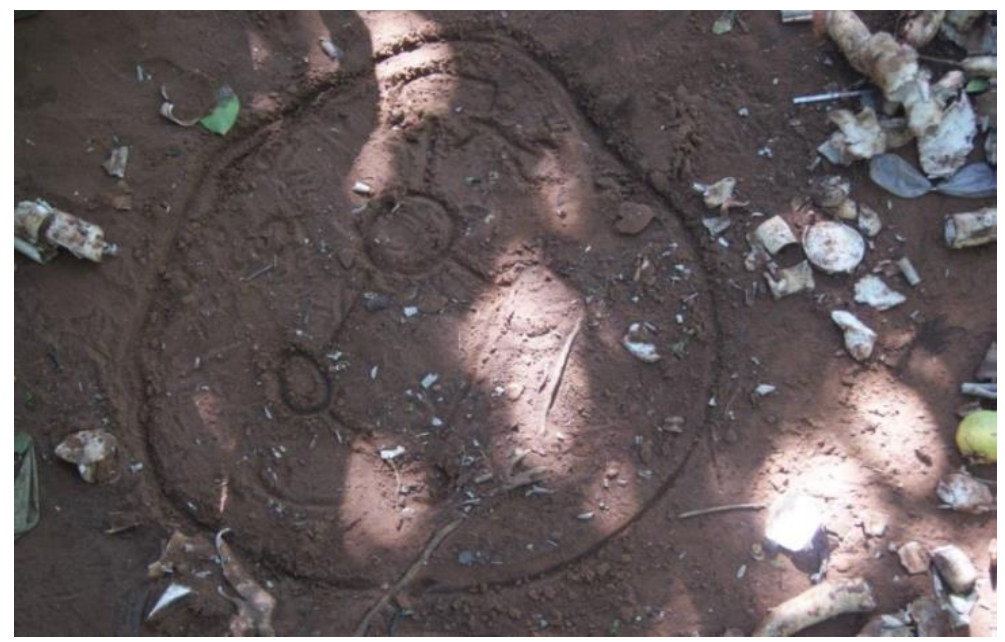

Figura 1: Representação da integração do tekohagasu Desenho feito por um dos participantes

Fonte: Crepalde (2014)

A fala seguinte, também, ilustra a construção do espaço como resultado de interrelações. Pode-se notar o uso repetido do pronome pessoal "ñande", evocando um "nós" e a formação de uma rede de relações que tece o ñande reko (nosso jeito de ser). Em guarani há dois pronomes pessoais para a primeira pessoa do plural: "ore" (nós, que exclui o ouvinte em 
relação ao grupo do falante) e "ñande" (nós, que inclui o ouvinte no grupo do falante). A expressão tekoha'i, composta de tekoha mais a partícula “i”, que indica diminutivo, contrapõe-se à expressão tekohaguasu, composta pelo substantivo tekoha e pelo adjetivo guasu (grande), indicando que as famílias tem seus espaços menores que podem se integrar em um espaço maior. Na fala abaixo, percebe-se que a expressão tekohagasu tem a ver com um território, um espaço físico no qual possam ir e vir, realizar o oguata (caminhar), mas tem a ver, também, com uma rede de relações sociais e políticas e tem a ver com uma fronteira étnica que estabelece um dentro e um fora. Nesse sentido, ñande (nós) passa ser ore (nósexclusivo), ou seja, quando um Kaiowa diz ore retã (nosso território) está se referindo a um território que exclui o ouvinte, demarcando por meio do pronome uma fronteira, um jeito de ser, um espaço exclusivo do grupo ao qual pertence o falante.

Koãnga, ko hera tekoha, tekoha'i pe, ardeia pe tekoha (Hoje, o nome tekoha, tekoha'i, um tekoha pequeno, a aldeia é um tekoha). Ha tekoha guasu ko pe ñande retã karai território (Mas o tekoha guasu é o nosso território, como o território do branco e o país). Tekoha guasu ñande demarca ñande mba'e, kohape liberdade ñande rekohape ñande pohã, ñande ka'aguy oheka oina yvyra pyre (O tekohaguasu demarca nossas coisas, nosso lugar de liberdade, nosso remédio, nossa mata para fazer a coleta). Entonces, a partir que ñande jademarcava tekoha guasu, nande jamendavapa tekoha jaimenda para jaguata koape jaguata hãgua (Assim, com a demarcação do tekohaguasu, podemos andar e ligar um tekoha no outro). Dourados, Ka'arapo, Jaguapire, Cerro Kora. Jakotevẽ ñande tekohaguasu ha upeicha ñande reko. (Os tekoha das cidades de Dourados e de Caarapo, e os tekoha das reservas Jaguapire e as terras de Cerro Kora).

Tanto o desenho quanto a fala acima remetem à dinâmica do processo de construção do espaço-tempo maior, pois outras noções de tempo e de espaço, outras formas de interação, outras histórias são colocadas em jogo. Para Massey (2009), o espaço deve ser compreendido como uma produção aberta e contínua, uma construção em devir que não é captada por uma imaginação, um constructo teórico que tente à força ordenar e negar essa multiplicidade.

As explicações dos kaiowa rementem às observações da referida autora, já que falam em um processo de mudanças constantes e das estratégias e dos conhecimentos que advém desse processo bastante complexo. Falam da construção de um espaço e de um tempo que se estabelece no mover-se, no expandir-se com o espaço, um mover-se que nos dias atuais faz-se com elementos negociados na fronteira com outras culturas.

Os kaiowa caracterizam-se por criarem constantemente alternativas para solucionar seus problemas, o que, muitas vezes, confunde-se com aculturação e perda de identidade. No entanto, são seres atuando em fronteiras culturais, sobretudo na fronteira com a cultura dos 
karai (brancos) e buscando construir sentido nesse turbilhão conflituoso, no qual não faltam violência física, psicológica e violação de direitos.

$\mathrm{O}$ fato de terem uma fronteira étnica não rígida permite-lhes uma variedade de possibilidades de solução de problemas práticos e políticos, no entanto, essa abertura, também, permite a entrada de outros problemas. Nos tekoha visitados, podem-se observar bens materiais que adquirem no mercado dos não índios ou que coletam nas ruas das cidades quando praticam o jeheka (coleta).

O contato com os karai permitiu-lhes experimentar e incluir, nas práticas sociais, elementos que passaram a ser necessários, como sal, açúcar, utensílios domésticos, instrumentos de plantio, veículos para a locomoção, etc.. Alguns elementos vieram a facilitar a vida, porém outros, como itens de alimentação, têm provocado doenças que, segundo os mais velhos, não existiam. Hoje, sofrem de alcoolismo, obesidade, diabetes e outras doenças decorrentes dessa nova dieta alimentar.

As escolas fazem parte da vida dos kaiowa desde o início do século passado e foram compreendidas, a princípio, como uma estratégia de luta, pois os Kaiowa acreditavam que as escolas possibilitariam a aprendizagem da língua portuguesa e de outros conhecimentos que os fortaleceriam para enfrentar as demandas contra os karai. Eles, no entanto, não esperavam que, por meio das mesmas escolas, seriam transmitidos outros valores, outros conhecimentos e geradas necessidades que acabariam provocando conflitos.

A fala abaixo de um participante de quase setenta anos ilustra a relação da cultura kaiowa com a cultura dos karai (brancos).

O chiru é um santo escrito, né? Hoje, não usa mais jekoky (dança indígena), só usa aquele tuk, tuk, tuki,...(referindo-se à música eletrônica) nois precisa de colégio. Antigamente não ganhava, não trabalhava em troco de dinheiro, trabaiava a troco de feijão, de galinha. E hoje como tem colégio... a gente, a ideia. A gente vê os branco gasta, nois que tamem, poxa! Não, não usava ropa. Era aquela coisa ....(gesto de uma bata). Agora nois vimo o sistema do branco, nois qué usa tamem, poxa. Antigamente nois não comia assim coisa de branco. Comia coisa assado e fervido. Hoje, se não toma café não vive também. Por isso que falo, o colégio tirou muito nossa ideia de como era antigamente. O colégio e a TV. A gente vê aquele imagem ali (gestos de coisa em movimento e atraente) a gurizada fica de olho estalado na TV. Até no colégio tira a ideia dele. O branco tem de ter paciência porque ele que invento colégio. O branco tirou nossa ideia. A ideia do índio é muito diferente.

Apesar do direito a uma escola diferenciada, resguardado na Constituição Brasileira de 1988, muitas práticas educacionais seguem a "cartilha" da pedagogia dos karai. Noções de beleza, de higiene, de sexualidade, de quantidade, etc. são passados como conceitos 
inquestionáveis e superiores em relação aos significados elaborados pela experiência kaiowa no mundo.

As escolas são atualmente arenas de contenda pelo comando e pelo currículo. São instâncias de poder e geram também recursos financeiros e bens materiais, passando a ser objeto de disputa entre os Kaiowa. Por esse espaço de conflitos escamoteados, passam crianças e adolescentes que convivem com os choques culturais, aprendendo a andar na fronteira fluida e indefinida, desafiando tanto o modo tradicional de ser como o modo karai de ser, subliminarmente imposto pelas escolas e pelas igrejas que frequentam.

As igrejas, principalmente pentecostais, foram aceitas pelos kaiowa da mesma maneira que as escolas, pois significavam, além da possibilidade de praticar a religiosidade kaiowa, controle e educação dos adolescentes, bem como acesso a bens materiais oferecidos pelas missões evangélicas e por grupos religiosos. Na fala dos kaiowa, frequentemente fazem-se alusões à demonização dos próprios kaiowa crentes às práticas religiosas tradicionais que, segundo eles, têm a função de manter o diálogo entre o mundo visível e invisível e são fundamentais nos processos educacionais, pois por meio delas aprendem-se linguagens e significados por meio do m’boe (reza), expressão que também significa ensinar.

O tekoha, dessa maneira, é constituído de vários movimentos que tem ponto de saída e chegada, mas são jornadas que estabelecem tempos e geografias próprias. O ir e o vir obedecem ao tempo das necessidades, a um tipo de fluxo de vida que desenha movimentos carregados de conflitos em um território que disputam palmo e que inclui as ruas das cidades, as beiras de estrada, de córregos, etc..

É nesse mover-se que descrevem a geografia kaiowa que não cabe em mapas, nem em fronteiras delimitadas por marcos fronteiriços artificiais como cercas e muros. Nas falas dos kaiowa, não faltaram críticas dos mais velhos à influência dos karai. Criticaram as casas muradas e de alvenaria que são construídas nas reservas, criticaram os inúmeros empréstimos que marcam a língua avañe'e) e criticaram o afastamento da cultura e a adesão a outras religiões, etc..

Essas críticas, no entanto, precisam ser entendidas dentro da dinâmica da política kaiowa, uma vez que muitos dos que criticam falam jopora, usam bens materiais dos karai e muitas vezes frequentam igrejas evangélicas. Essa contradição faz parte do jogo político e é justificada pela cultura, pois é dever dos mais velhos criticar, relembrar e defender os conhecimentos tradicionais. Os criticados, por sua vez, também vivem nesse entrelugar, pois 
buscam o equilíbrio entre o corpo e a alma em religiões dos karai e na medicina dos karai, no entanto, não deixam de recorrer aos rezadores tradicionais tanto para o fortalecimento da religiosidade como também para os males do corpo.

As explicações dos Kaiowa permitem dizer que o fio que sustenta a identidade no meio dessa dinâmica é a necessidade da pertença. Ficou claro, nas visitas e nas falas, que se pode usar elementos de outras culturas e experimentar outros valores, porém ficou claro, também, que se deve estar ligado a uma família extensa, ter uma função nessa trama familiar, nessa construção emocionada que envolve afeto e lealdade, conflitos e solidariedades. No entanto, para pertencer, para participar desse jogo, é preciso mais que afetos e lealdades, é preciso saber os critérios de julgamento, as regras do jogo político estabelecido, uma espécie “ética relacional” no entender de Massey (2009).

Dessa maneira, ser kaiowa, neste momento histórico, passa por usar jeans, celular, dançar rap, sertanejo, etc., mas passa também pelo vínculo da pertença. Para tanto, saber lidar e atuar num espaço sempre aberto Massey (2009), sempre em risco, cheio de fraturas e instabilidades e possibilidades é o desafio dos kaiowa contemporâneos. Essa luta pela pertença pode ser ilustrada pela metáfora: os kaiowa sem sua cultura são apenas carunchos da terra, elaborada por um dos participantes. Isso significa que a possibilidade de não vicejar, de não conseguir manter a vida é real. Não se pode mover de qualquer forma, pois se corre o risco de não ser reconhecido nem pelos contemporâneos nem pelos ancestrais. Corre-se o risco de perder o sentido da vida e querer dar fim a ela por meio de suicídios ou entregar-se a vícios e comportamentos maus (teko vai), o que efetivamente tem ocorrido. Assim, os Kaiowa devem manter sua cultura, devem saber manter o diálogo constante, o que implica em saber articular os novos conhecimentos e lidar com a diversidade de problemas que se apresentam.

Embora alguns kaiowa tenham relógios de pulso e outros falem em cumprir jornadas de trabalho de oito horas, usam, também, expressões que remetem a um tempo que se manifesta nas mudanças da natureza, como o final do tempo frio, dos galhos secos, da diminuição dos movimentos, da falta de alimentos, etc.. Usam outras expressões que se referem ao despertar da vida, do nascimento de flores, da correria do sexo e da gravidez da natureza. O mover-se pelo meio ambiente, neste momento histórico, é permeado por elementos tradicionais e novos e utilizado segundo os interesses de cada família extensa em dados momentos. 
As conversas com os Kaiowa ocorreram em tekoha em reservas, em terras retomadas, em beira de estrada, em terras em litígio e até nas ruas da cidade. As explicações dos kaiowa chamaram a atenção para o problema da exiguidade de espaço bem como a reiteração da luta pelas terras. Nesse sentido, a expressão tekoha ganha uma conotação de política externa e demarca um jeito de ser, sobretudo em relação ao modo de ser dos karai.

As falas, nesse sentido, são discurso políticos que destacam o respeito que nutrem pelo meio ambiente e, ao mesmo tempo, acusam os desmandos e a insensibilidade dos não índios que usam as terras com o intuito de gerar lucros. Essas falas vêm acompanhadas de explicações sobre como lidar com a terra sem profaná-la e por metáforas como a mata é "nosso farmácia" e "nosso mercado". Esses discursos remetem também aos tekoha antigos e a uma toponímia kaiowa que nomeia em avañe'ẽ córregos e lugares, mantendo uma toponímia paralela.

Esse sentido político de tekoha intensifica-se nas atyguasu (assembleias), que envolvem a participação de outros grupos étnicos, sobretudo dos Guarani, nas quais avaliam a situação em que se encontram, tomam decisões e reforçam a luta pelas terras tradicionais. Essas assembleias funcionam também como grandes encontros, e, nelas, são realizadas manifestações culturais, como cantos, danças e rezas (CREPALDE, 2014).

Nesses momentos, representantes de famílias extensas de vários tekoha fazem-se presente e tomam a palavra para fazer suas reivindicações, participar da luta unificada e fortalecer o ñande reko (nosso jeito de ser). O tekoha, nesse contexto, é concebido como corpo necessário para produção da vida kaiowa. Colocam-no como condição essencial para a sobrevivência das gerações presentes e futuras e para a construção de uma identidade que se realiza em relação a esse espaço. E na defesa e na reivindicação do tekoha, recorrem à memória dos mais velhos para identificar e recuperar suas terras bem como aos poderes dos rezadores, o que acaba sendo um grande momento de aprendizagem.

Todos esses elementos fazem do tekoha o resultado de múltiplas trajetórias das famílias extensas (MASSEY, 2009), e, ao mesmo tempo, um campo de resistência, sobretudo em relação a cultura dos karai, surgindo como uma alternativa de produção de vida e de futuro. O tekoha é um agente que assume uma posição radical contra os processos de colonização, requerendo suas próprias formas de estabelecer a uma ordem e uma política.

A expressão tekoha evoca a complexidade da maneira kaiowa de pensar, pois remete a um conjunto de signos organizados à moda kaiowa de representar que evocam uma carga 
semântica intensa, passando, de súbito, significados que não cabem em categorias estatizantes e disciplinares.

O tekoha, nesse sentido, aparece também como uma manifestação artística, pois as conexões, as forças das emoções que o compõem fazem dele um artefato cultural composto de inúmeros elementos. Ao contemplá-lo, ao percebê-lo nessa complexidade vêm à tona as sensações que as artes provocam. À noite, quando os cantos as danças, as rezas, o som dos mbaraka, o movimento dos corpos, o fogo, as estrelas, a escuridão se confundem, surge uma obra de arte em devir.

O espaço-tempo tekoha expande para todos os lados, para cima, para os patamares do céu, para baixo, nas pisadas firmes, no reconhecimento e no apego à Mãe-terra, para os lados das matas, das roças, dos rios em inscrições rizomáticas que dizem sobre o encontro de corpos humanos e não humanos que se marcam, imbricam-se, esculpem-se, fazendo vir a ser um lugar, um contexto, um ninho de pertença, uma arena de conflitos, uma condição de expressão do entrecruzamento de forças e de emoções (TEIXEIRA, 2010), um sistemas simbólico, um lugar construído nos contínuos processos de tekohalização, expressão que remete ao um jeito de deixar fluir a construção do espaço (LITTLE, 2002). O processo de tekohalização é um movimento, um jeito de dar vazão a uma força que se expande e gera um lugar entrelaçado pela linguagem kaiowa.

Se as reflexões da LC permitem pensar o tekoha como uma metáfora de um corpo que emerge do contato com o meio ambiente, com base nas contribuições teóricas de Massey (2009), o tekoha dos Kaiowa pode ser pensado como um espaço geográfico e social que resulta da interação entre tudo que o compõe. Ele emerge dos jogos políticos e das estórias e trajetórias de famílias extensas, que lutam para a construção de um "nós", para a construção de um espaço de pertença. $\mathrm{Na}$ linha de raciocínio da referida autora, entendemos que o tekoha resulta de uma intricada trama de relações, e para refletir sobre ele importa sobremaneira perguntar sobre como essas relações ocorrem. Ademais, devem-se evitar categorias e conceitos que contribuam para o apagamento de heterogeneidades e das contradições (MASSEY, 2009, p. 160), das quais emergem o sentido e o lastro com o mundo.

\section{Considerações jamais-finais}

Acreditamos que a tentativa de fazer ponderações sobre as explicações de tekoha pelos Kaiowa com base na literatura sobre a cultura desse grupo étnico e em conceitos e reflexões de diferentes áreas do conhecimento foi acertada. 
Nesse sentido, entendemos que as reflexões de Massey (2009) inspiraram-nos a olhar para a dinâmica das relações que compõem o processo e para categorias espaciais, como periferia, globalização, espaço, lugar, cultura, etc.. Suas reflexões alertaram-nos sobre como os Kaiowa vivem em espaços de constante trânsito de símbolos, valores e conceitos de culturas diferentes, construindo o tekoha como um espaço aberto e em devir. Ainda inspirados pelos conceitos de dinamicidade e política da referida autora, foi possível pensar nas habilidades do Kaiowa em viver no interstício de culturas e lidar com elementos culturais diferentes e, ao mesmo, saber pertencer ao grupo étnico, o que requer habilidades para reconhecer as táticas políticas inter e intraétnicas desenvolvidas nesses contextos.

As reflexões da referida autora levaram-nos a não perder de vista que, para pensar o tekoha, deste momento histórico, deve-se considerar o contexto cultural dos Kaiowa, mas também o contexto sociopolítico-econômico e cultural globalizado que o atravessa. Nessa dialética, nessa luta entre premissas diferentes, o tekoha surge, como glocal, um lugar influenciado pelos processos de globalização, mas que também influência e resiste, impondose como uma alternativa a esses processos. Essas reflexões levaram-nos a pensar que a expressão tekoha encerra a ideia de espaços culturais e geográficos construídos por processos interacionais dinâmicos.

As reflexões de Barth $(1993,2000)$ sobre fronteiras étnicas ajudaram-nos a pensar sobre as fronteiras étnicas dos kaiowa e permitiu-nos perceber que, embora haja uma fronteira cultural fluida, ela circunscreve um modo de ser, e impõem critérios de julgamento para o pertencimento. Com base nessa reflexão foi possível pensar na fluidez das fronteiras culturais, mas também nos laços que são construídos a começar na família extensa e como esses laços são os limites para a construção da identidade kaiowa.

Foi acertada, também, a escolha da teoria desenvolvida no âmbito da LC, pois tal teoria ajudou-nos a pensar a linguagem como um espaço de entrelaçamento dos elementos que a compõem e como um elemento no processo de construção dos espaços físicos e culturais. Essa perspectiva teórica destaca a importância do contexto cultural para se compreender os fenômenos da linguagem, chamando a atenção para o aspecto motivacional e não apenas arbitrário da linguagem. Por meio dessa teoria, foi possível compreender as metáforas kaiowa, não como figuras de linguagem, mas como premissas fundamentais e como processo cognitivo que constrói sentido com base em conhecimentos prévios e na relação entre as propriedades dos elementos do mundo. 
Ao analisarmos interdisciplinarmente as explicações de tekoha, foi possível perceber como espaço e tempo são significados que emergem da experiência de estar no mundo e que emergem das fadigas, de ciclos da natureza, de transformações corpóreas, de luas, de invernos, de floradas, de cios, etc.. Nesses movimentos, constroem matemáticas, físicas, químicas, linguagem, medicinas, histórias, artes e religiosidades, saberes inter-relacionados que formam um todo indissociável.

Nesse sentido, tivemos a ousadia de pensar o tekoha como arte, como manifestação estética que não se dissocia de outros aspectos da vida. Assim, o tekoha é um artefato simbólico, uma síntese dos movimentos políticos, das histórias, das trajetórias, das emoções, dos conhecimentos, dos conflitos, das continuidades e rupturas que fala de uma alternativa de ser no mundo, que emerge do mundo e mantém seu lastro com ele.

Por fim, acreditamos ser importante dizer que a experiência de tentar olhar interdisciplinarmente para as explicações dos kaiowa sobre seus tekoha foi uma tarefa extremamente difícil, mas que ampliou nossa capacidade de reflexão sobre a realidade. Esse exercício permitiu-nos pensar na complexidade das categorias de espaço, tempo, cultura, linguagem, relações sociais, fronteiras culturais, etc. com base na cultura kaiowa. Além disso, nos possibilitou refletir sobre a complexidade dos significados kaiowa que são elaborados por um modo de ser holístico, um sistema aberto, uma síntese sempre a ser terminada.

Essa experiência mostrou-nos que interpretações sobre o que seja tekoha são inesgotáveis e serão sempre parciais, haja vista a complexidade que evoca a expressão; no entanto, ficou a sensação que fora de interpretações interdisciplinares pode-se reduzir muito o que essa expressão encerra.

Queremos dizer, ainda, que, apesar de ter utilizado o trabalho de Benites (2012), um antropólogo kaiowa, e ter, em certa medida, tomado cuidado com conceitos eurocêntricos (KUSH, 1999), não há como livrarmo-nos do contexto impregnado do pensamento ocidental em que vivemos, o que nos coloca em contradição e em risco permanente de cair nos constructos que tentamos evitar. No entanto, acreditamos que nossas reflexões possam contribuir com trabalhos que queiram fugir de categorias etnocêntricas estatizantes e pensar no processo de tekohalização como um movimento dinâmico e em devir que esculpe corpos e lugares, inaugurando constantemente um espaço-tempo, uma ação desencadeada pela força e pelo desejo de querer ser o que se pensa ser. 


\section{Referências}

ASSIS, Fernandes de. Ñe'ẽ Ryru Avañe 'ẽ: dicionário Guarani-Português. São Paulo, ed. Própria, 2000.

BARTH, Fredrik. O guru, o iniciador e outras variações antropológicas. Trad. John Cunha Comerford. Rio de Janeiro: Contra Capa Livraria, 2000.

. Balinese worlds. Chicago and London: University of Chicago Press, 1993.

BENITES, Tonico. A escola na ótica dos Ava Kaiowá: impactos e interpretações indígenas. Rio de Janeiro: Contra Capa Livraria, 2012.

COSTA, Luciano Bernardino. Imagem dialética/imagem crítica: um percurso de Walter Benjamin a Georges Didi-Huberman. In: V Encontro de História da Arte, 2009, Campinas. Anais... Campinas: Unicamp, 2009. p. 87-93.

CREPALDE, Adilson. A Construção do Significado de Tekoha pelos Kaiowá do Mato Grosso do Sul. Tese (Doutorado) - Universidade Federal do Rio Grande do Sul, Instituto de Letras, Programa de Pós-Graduação em Letras, Porto Alegre, RS, 2014.

GIBBS, Raymond W. Embodiment and Cognitive Science. Cambridge University Press: New York, 2006.

KÖVECSES, Zoltán. Metaphor in Culture: Universality and Variation. Cambridge University Press: New York, 2005.

KUSH, Rodolfo. América Profunda. 4ª ed. Buenos Aires: Biblos, 1999.

LAKOFF George; JOHNSON, Mark. Metaphors we live by. London: The university of Chicago press, 2003.

LITTLE, Paul E. Territórios sociais e povos tradicionais no Brasil: por uma antropologia da territorialidade. Brasília: UnB, 2002. Série Antropologia n 322. 32p.

MASSEY, Doreen. Pelo espaço: uma nova política da espacialidade. Tradução Hilda Pareto Maciel; Rogério Haesbaert. 2a . Ed., Rio de Janeiro: Bertrand Brasil, 2009.

TEIXEIRA, Felipe Charbel. Aby Warburg e a pós-vida das Pathosformeln antigas. História da historiografia, Revista Ouro Preto, n. 05, setembro, 2010. 134-147. 